\title{
The protection and manipulation of electrical-resistance strain gauges of the bonded- wire type for use in concrete, particularly for internal strain measurement*
}

\author{
by G. Hondros, B.E., A.M.I.E.Aust., A.M.Amer.S.C.E.
}

\section{Contribution by J. D. Todd, M.A., D.Phil. \\ (University of Oxford)}

I read Mr Hondros's paper with great interest as I have undertaken a fair amount of work in this connexion at the University of Oxford.

I employed a very similar technique in 1950; the resistance strain gauge was mounted on brass foil 0.003 in. thick and then waterproofed by a number of different methods using various lacquers and waxes. The results were very disappointing, however. All gauges were thoroughly tested for earth resistance after waterproofing, both in air and again after being submerged in water for a week. Any faulty gauges were then discarded. The satisfactory gauges were placed in various concrete test specimens but, by the end of the curing period, less than $50 \%$ of the gauges had an earth resistance of over 10 megohms: this was found to be a minimum requirement if satisfactory operation was to be obtained.

It was found that the only really satisfactory solution was to encase the gauge completely in brass foil. ${ }^{(1)}$ The gauge was mounted in the normal manner on a brass foil base. A cover was pressed in brass foil to give sufficient clearance over the gauge and leads; this was then soldered to the base. The gauge leads were soldered to wires which were taken through a copper tube of small bore and suitable length, the tube being soldered to the cover. This meant that the gauge was completely waterproof, robust, and had a box-shaped section for increased rigidity. With this type of waterproofing very few failures were encountered in over 150 gauges, even though they were submitted to rough treatment.

I would be interested to learn from the author what percentage of gauges have to be discarded before they are placed in concrete; also the percentage that give really satisfactory service when the concrete is fully cured and submitted to test.

\section{Contribution by A. J. Ashdown}

There appears to be a discrepancy in Mr Hondros's paper in the balance of forces in the test beam.

The stresses in the steel of the test beam as shown in Figure 10 show that the steel force at a load of $8,000 \mathrm{lb}$ is $40,000 \times 0.22=8,800 \mathrm{lb}$; this force divided into the bending moment $(8,000 \times 9) / 8,800=8.2$ in. is the lever arm, but the effective depth by scaling is less than 7 in.

This disparity between the actual stress in the steel found by strain measurement and the force required to balance the bending moment within the beam has been observed in many beams published and unpublished; it is more noticeable in beams with a small percentage of steel,

\footnotetext{
*Pages 173-180.
}

and should not be considered as in any way invalidating the author's measurements.

It will be seen from Figure 10 that if the line 8 is extrapolated beyond the visual cracking line back to zero load the stress in the steel is around $-10,000 \mathrm{lb} / \mathrm{in}^{2}$. If this point is considered to be zero stress, the lever arm will in effect reduce to about $6.5 \mathrm{in}$., which is a reasonable figure.

An explanation of this phenomenon may lie in the different elastic properties of the steel and concrete during the development of bonding. The strain energy in tensioning the concrete around the steel up to cracking is transmuted in some way to reduce the stress in the steel; otherwise one would expect a large jump in steel stress at concrete cracking, with the slope of further stress pointing to zero.

Shrinkage effects could not reasonably account for a $10,000 \mathrm{lb} / \mathrm{in}^{2}$ difference in stress.

\section{Reply by the author}

The beam (Figure 8) and the cylinder (Figure 1) were examples drawn from current research projects being conducted at the University of Western Australia and were recorded to illustrate the different applications of the gauge methods. $\mathrm{Mr}$ Ashdown has perceived the apparent discrepancy in the tensile behaviour of the beam, which has been observed to occur in a number of members of similar dimensions. The beams were proportioned so that their span-depth ratio, in this instance 6, fell between the range of balanced design (12-20) and the girder-wall ${ }^{(1)}$. Visual cracking in the beam occurred almost simultaneously on the tension face at two planes approximately $3 \mathrm{in}$. each side of the centre-line and was followed by cracking at the plane $8 \frac{1}{2}$ in. inside the right support. This could account for a substantial reduction in the observed steel strains. Mains ${ }^{(2)}$ has shown that peak values of bar forces occur at planes of cracking and can exceed those at intermediate planes by as much as $30 \%$. However, this does not entirely explain the deviation manifest in these squat beams and one must consider some form of strain-energy transmutation in the formation of bond as suggested by $\mathrm{Mr}$ Ashdown.

In answer to Dr Todd, it may be stated that many combinations of lacquers, waxes, bitumens, and types and shapes of metal mount were investigated before the adoption of the methods described in the paper. A considerable effort was made to develop a brass envelope but results were not good. Our experience was that the neck where the leads emerge from the envelope was a continuous source of trouble, particularly in gauges required for long-term tests.

Since the standardization of the techniques, a record of 276 shim gauges has been kept. Of these, 8 gauges 
were complete losses, 14 gave insulation readings less than $10^{3}$ megohms and 7 were found to possess slightly imperfect gauge-shim adhesion. However, the latter 21 gauges were serviceable, as they were used in short-term tests, and in tensile strain fields.

In the early, developmental phases of the work, faulty gauges were rejected for two main reasons: because of low insulation resistance determined by the leakage test, and because of partial and imperfect sticking of the gauge to the shim, suspected from the erratic behaviour of the gauges during straining. From post-mortem examination of gauges carefully removed from crushed specimens, it has been found that some, although adequately insulated, were not properly cemented to the brass. The cause of this type of failure appears to be the condition of the cement used. Cement drawn from tubes which have had previous use and have been stored for some time gives a high incidence of such failures. This may be attributed to the evaporation of the solvent from the cement in the loosely sealed tube, and can be avoided by preparing gauges in batches containing sufficient numbers to consume a tube of cement, or, as the cost of the glue is small, to discard used tubes in favour of fresh ones.

Generally, very low insulation resistance is accompanied by reduction of the gauge-shim adhesion which, before the gauge is placed into the concrete, may be good. In these cases, moisture penetrates the protective layers of the gauge, is absorbed by the paper backing, reducing and in some cases completely destroying the bond with the brass mount.
In tensile strain measurements slight imperfections in gauge-shim adhesion do not seriously impair the efficiency of the transducer. However, compressive strain measurements are more exacting and require maximum and uniform bond between the gauge and shim. These observations conform with the opinion expressed by Jones and Maslen. ${ }^{(3)}$

The need for alternative materials in the event of supply difficulties has revealed that Philips glue may be replaced by Durofix and Sira Wax by a bitumen with a low melting point (Shell Mexphalate) without reducing the effectiveness of the methods.

\section{REFERENCES}

1. TODD, J. D. Waterproofing electrical-resistance strain gauges. Engineering. Vol. 171, No. 4434. 19th January 1951. p. 67.

2. Uhlamm, H. L. B. The theory of girder walls with special reference to reinforced concrete design. The Structural Engineer. Vol. 30. August 1952. pp. 172-181.

3. MAINS, R. M. Measurement of the distribution of tensile and bond stresses along reinforcing bars. Journal of the American Concrete Institute. Vol. 23, No. 3. November 1951. pp. 225-252.

4. JONES, E. and MASLEN, K. R. The physical characteristics of wire resistance strain gauges. London, H.M.S.O., 1952. pp. 44. ARC Technical Report R and $M 2661$. 